\title{
BIBECHANA
}

A Multidisciplinary Journal of Science, Technology and Mathematics

ISSN 2091-0762 (Print), 2382-5340 (0nline)

Journal homepage: http://nepjol.info/index.php/BIBECHANA

Publisher: Research Council of Science and Technology, Biratnagar, Nepal

\section{Morphological study on particulate matter of Kathmandu valley}

\author{
Jyoti Rauniyaar ${ }^{1}$, Girja Mani Aryal ${ }^{2}$, Bhanu Bhakta Neupane, ${ }^{3,4}$ \\ ${ }^{1}$ Amrit Campus, Tribhuvan University, Kathmandu, Nepal \\ ${ }^{2}$ Research Center for Applied Science and Technology, T. U., Kathmandu, Nepal \\ ${ }^{3}$ Central Department of Chemistry, Tribhuvan University, Kathmandu, Nepal \\ ${ }^{4}$ Kathmandu Institute of Applied Sciences, Kathmandu, Nepal \\ *Email: newbhanu@gmail.com
}

Article history: Received 13 May, 2018; Accepted 06 September, 2018

DOI: http://dx.doi.org/10.3126/bibechana.v16i0.19190

This work is licensed under the Creative Commons CC BY-NC License.

https://creativecommons.org/licenses/by-nc/4.0/

\section{(c) (i) (8)}

\begin{abstract}
Air borne particulate matter (PM) depending on size, shape, concentration, and chemical composition can cause multitude of health issues. In this study, we report the morphological study of dust samples obtained from twenty different locations of Kathmandu valley by imaging the sample directly by a bright field optical microscope. We find that the average size of particles in all the samples examined below 10 micrometer. Individual examination of particles revealed that significant number of particles asymmetric. The observation of asymmetric particles having aspect ratio as high as 20 may suggest that asbestiform particles exist in all the dust samples examined.
\end{abstract}

Keywords: Particulate matter; bright field optical microscopy; dust samples; aspect ratio.

\section{Introduction}

Air pollution is one of the leading causes of death thorough out the world. The major contributors to air pollution are particulate matter (PM) and volatile organic compounds (VOCs). Particulate matter having size smaller or equal to ten micrometers $\left(\mathrm{PM}_{10}\right)$, that contains fine $\mathrm{PM}_{2.5}$ and course particles, contribute significantly to overall ambient air pollution. The $\mathrm{PM}_{10}$, contains inhalable particles which can penetrate to the thoracic region, and can deposit to the conducting zone of the respiratory system and even in alveoli inducing many pulmonary, cardiovascular, and other health problems. Many epidemiological and toxicological studies have suggested that PMs are linked with lung inflammation, respiratory cancer, vascular dysfunction, systemic inflammation, myocardial infarction, and exacerbation of existing conditions (like asthma, diabetes mellitus etc.). World Health Organization (WHO) estimates that around 0.8 million people die annually from PM exposure; with Asia alone contributing around $65 \%$ of total global burden [1-2] 
Kathmandu valley, with population of around 3 million, is one of the most densely populated, fastestgrowing, and polluted metropolitan areas in South Asia. It is reported that in Kathmandu valley PM alone contributes around $50-60 \%$ of total pollution burden [3-6]. The recent environment performances index (EPI), shows that air quality of urban areas of Nepal is very poor (ranked $177^{\text {th }}$ out of 180) [7]. The ambient annual-average $\mathrm{PM}_{10}$ concentration levels in core urban areas is reported to be in the range of $80-200 \mu \mathrm{g} / \mathrm{m}^{3}[3,4,6]$; which is roughly 2-5 times higher than the WHO standard of $40 \mu \mathrm{g} / \mathrm{m}^{3}$ [1]. It is also reported that the number of cardiovascular and pulmonary outdoor patients, and morbidity and morbidity rates of indoor patients are increasing $[5,8,9]$. The main sources of PM in Kathmandu city are industrial gases, photochemical oxidants, vehicular exhaust, burning of agriculture waste, smokes from brick kiln and industries, dust from construction sites etc.

Health effects caused by PM and VOCs depends both on concentration (or dose) and chemical and morphological composition. Studies made in cities of developed countries reported that cardiovascular and pulmonary related morbidity and mortality rates positively correlate with heavy metals (like lead, nickel, cadmium, mercury, and vanadium) enriched PMs and several volatile carcinogenic compounds $[10,11]$. Such studies are very scarce for the cities of developing countries. In this study, we examined the dust samples of different locations of Kathmandu valley by using a bright field optical microscopic technique. By using direct image analysis, we report the size and asymmetry of PM particles in the all dust samples collected. Variation of size and asymmetry of particles in the samples collected at same location but at different height is also reported.

\section{Materials and Experimental Methods}

Dust samples were collected from twenty different locations of Kathmandu valley in the month of April. The sample collection site map is shown in figure 1. All samples were collected in dry sunny days in the time window $10 \mathrm{am}-4 \mathrm{pm}$. To collect the sample a pre-cleaned glass petri disc was used. The petri disc was placed at height of around 20 meter from the surface.

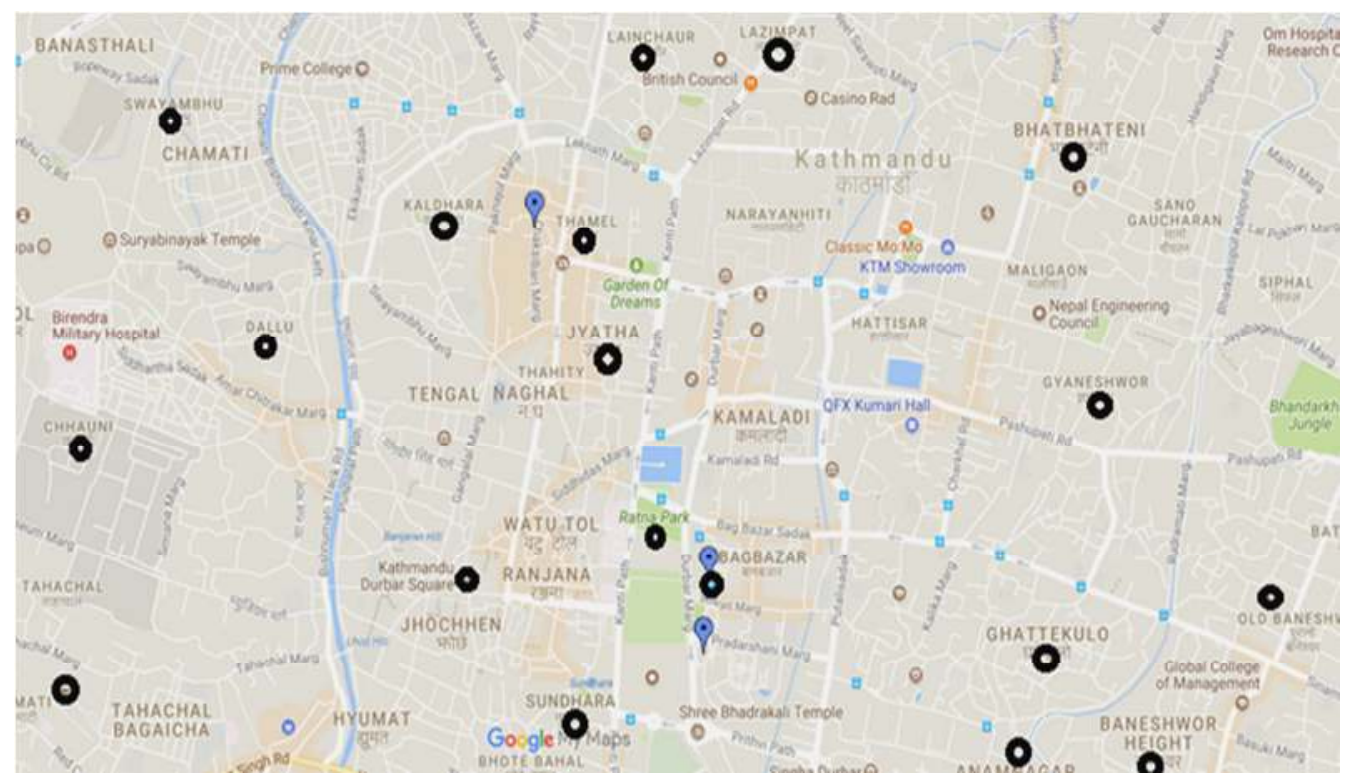

Fig. 1: A portion of goggle map of Kathmandu valley that shows approximate location of sample collection site. In the map, the collection sites are indicated by a donut shaped structures. 
A small amount of dust sample was transferred in a microscopic cover slide. The sample was imaged by using a Amscope bright field microscope (Amscope, USA) equipped with a software controlled CMOS camera. Around 6-20 images were collected for each sample and the number of particles per field of view was in the range of 200-400. The field of view was measured by using high precision glass slide having 10 micrometer spaced linear lines. The collected images were imported to ImageJ (NIH, USA) software and analyzed to get size and asymmetry information.

\section{Results and Discussion}

The measured particle size for all twenty samples is shown in figure 2. It is obvious form the figure that for all samples particle size is below $10 \mu \mathrm{m}$ with average particle size in the range of $3.5-4.8 \mu \mathrm{m}$. The lateral resolution of the optical microscope system used in this study was around $0.5 \mu \mathrm{m}$, so limited resolution gives a small uncertainty in measurement in particle size. Although many optical microscopic approaches that can provide better resolution than a bight field microscope are in use [1315] microscope having resolution around $500 \mathrm{~nm}$ will help to resolve objects that have size of few micrometer. The lateral resolution $\left(D_{x y}\right)$ of the microscope system used in this work can be calculated on the basis of following equation [13].

$$
D_{x y}=\frac{\lambda}{2 N A}
$$

For the microscopic system used in this study the peak wavelength $(\lambda)$ of light source used is around 500 and numerical aperture of light (NA) is 0.5 . Using these parameters, above equation results $D_{x y}$ of $500 \mathrm{~nm}$.

Form figure 2, it is evident that particle size for all samples is below $10 \mu \mathrm{m}$. On the basis of this, we can say that all samples examined contain $\mathrm{PM}_{10}$. The source of $\mathrm{PM}_{10}$, as suggested in many studies could be vehicular exhaust, construction sites, burning of agricultural and organic wastages, brick kiln etc.

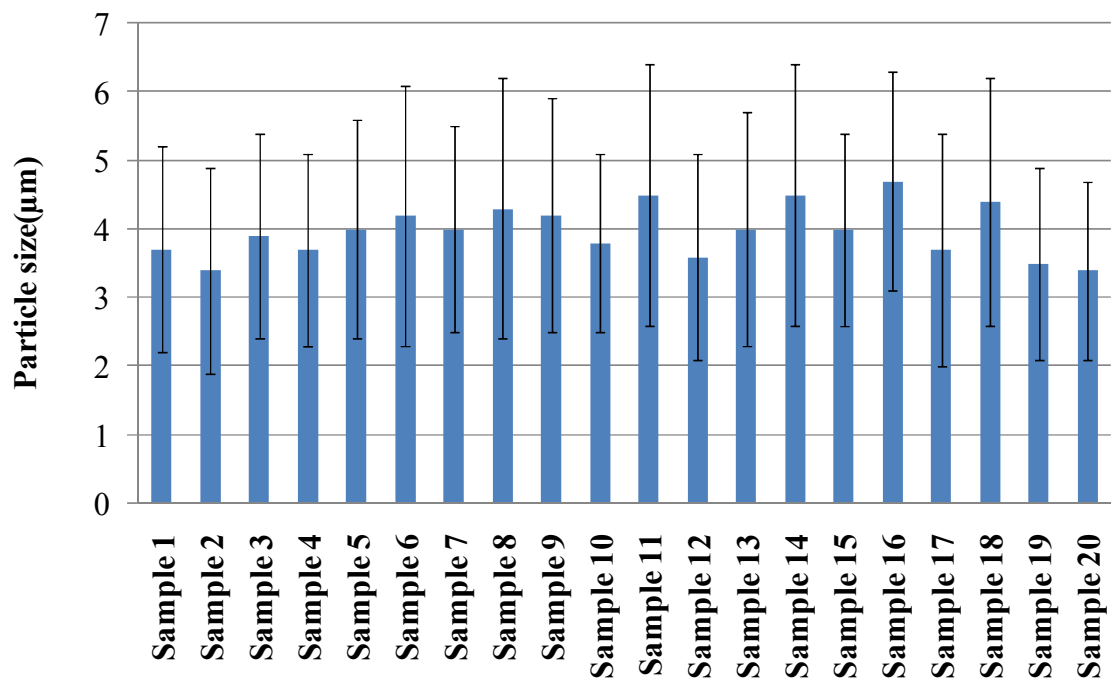

Fig. 2: The measured particle size for the samples 1-20. In the figure, error bars are shown as vertical lines. For each sample, error bar is reported as mean \pm standard deviation. 
We also measured the number of symmetric and asymmetric particles in each samples and the data are reported in figure 3. We chose aspect ratio as a parameter to classify a particle as symmetric and asymmetric. Here, as in literature, aspect ratio is defined as ratio of length of longest axis to length of shortest axis of a particle. If this ratio is below two we assigned the particle as symmetric and asymmetric if the aspect is higher than two.

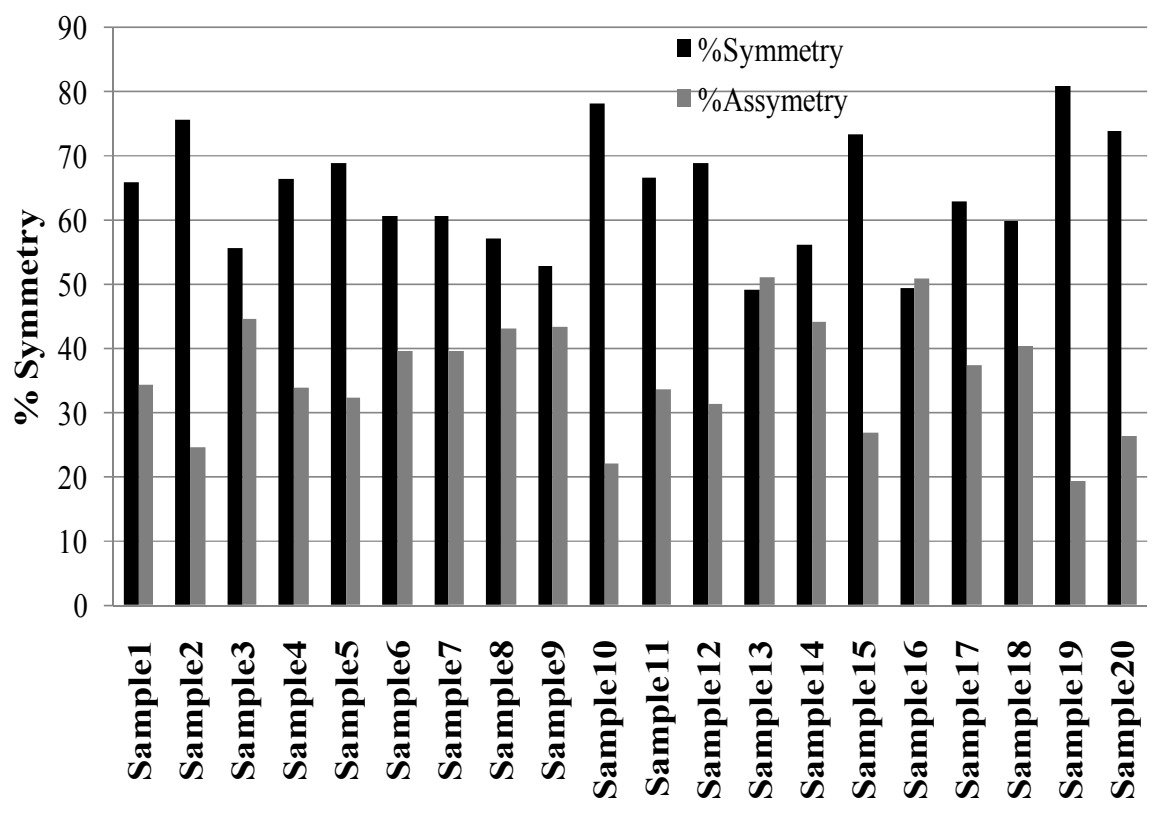

Fig. 3: Measurement on $\%$ of symmetric and asymmetric particles for the samples 1-20.

During measurement we found around $1 \%$ of the particles having aspect ratio as high as 20 . These high aspect ratio particles most likely are of asbestiform type. Although scientific study on source of these particles is not clear, it can be inferred that the materials used in construction such as cement, concrete etc. could be their origin.

We also examined the samples collected at different heights. The measured particle size for samples collected in three different heights $(20 \mathrm{~m}, 30 \mathrm{~m}$, and $40 \mathrm{~m})$ is reported in figure 4 . Interestingly, for the heights selected the particle size is similar within the standard deviation. Although we did not study the number density variation of particle with height, suggests that particles are homogeneously distributed in terms of morphology.

We also measured the number of symmetric and asymmetric particles for the samples collected at different height and data are reported in figure 5. As in previous case, we chose aspect ratio as a parameter to classify a particle as symmetric and asymmetric. If this ratio is below two we assigned the particle as symmetric and asymmetric if the aspect is higher than two.

As reported previously, for the samples collected at different height, we found around $1-2 \%$ of the particles having aspect ratio as high as 20 . 


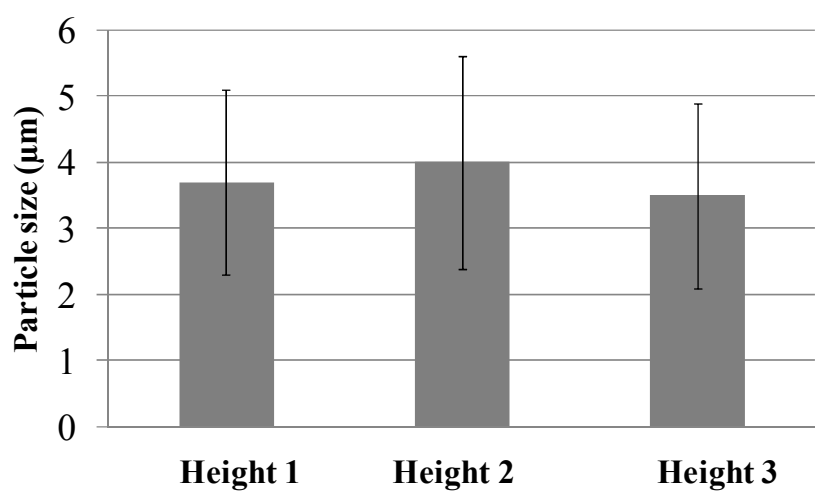

Fig. 4: Particulate matter size measured at three different heights; height 1 at $20 \mathrm{~m}$, height 2 at $30 \mathrm{~m}$, and height 3 at $40 \mathrm{~m}$ from the surface. In the figure, error bars are shown as vertical lines. For each sample, error bar is reported as mean \pm standard deviation.

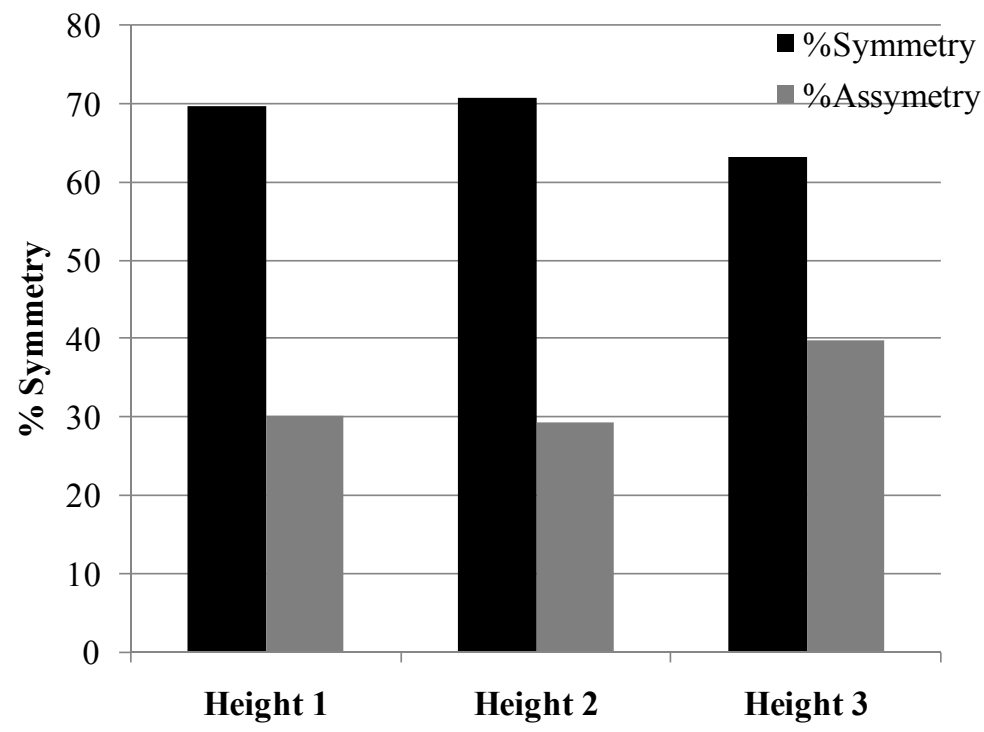

Fig. 5: Measurement on \% of symmetric and asymmetric particles for the samples collected at different height; height 1 at $20 \mathrm{~m}$, height 2 at $30 \mathrm{~m}$, and height 3 at $40 \mathrm{~m}$ from the surface.

\section{Conclusion}

We examined the particulate matter size and shape in the dust samples collected from twenty different sites of Kathmandu valley using bright field microscopic system. We found that all samples contained particulate matter of size at or below ten micrometer. In all the samples examined, we report that significant number of particles asymmetric and out of them around 1-2 \% with aspect ratio as high as 20. Existence of high aspect ratio particles could tell the existence of asbestiform type particles. 
Examination of samples collected at different height revealed that particles are homogenously distributed in terms of morphology.

\section{Acknowledgements}

We acknowledge Kathmandu Institute of Applied Science, Kathmandu, Nepal for providing optical microscopic system for data collection.

\section{References}

[1] WHO, Air Quality Guidelines: Global Updates, WHO Regional Office Copenhagen, Denmark, 2005.

[2] Health effects of outdoor air pollution in developing countries in Asia, Health Effects Institute, Boston, MA, 2004.

[3] D. Giri, K. V. Murthy, P. R. Adhikary, and S. N. Khanal, Ambient air quality of Kathmandu valley as reflected by atmospheric particulate matter concentrations $\left(\mathrm{PM}_{10}\right)$, Int. J. Environ. Sci. Technol. 3 (2006) 403.

[4] R. K. Aryal, B. -K. Lee, R. Karki, A. Gurung, J. Kandasamy, B. K. Pathak, S. Sharma, and N. Giri, Seasonal PM10 Dynamics in Kathmandu Valley. Atmospheric Environment, Atmospheric Environment $42(2008) 8623$.

[5] A. Gurung, and M. L. Bell, Bell Exposure to airborne particulate matter in Kathmandu Valley, Nepal. J. Expos Sci. Environ. Epidemiol. 22 (2012) 235.

[6] B. B. Pradhan, P. M. Dangol, R. M. Bhaunju, and S. Pradhan, International Centre for Integrated Mountain Development, Kathmandu (2012).

[7] EPI report, Air Quality, 2018, https://epi.envirocenter.yale.edu/2018-epi-report/air-quality, Sept 52018.

[8] H. S. Shrestha, O. Nepal, K. Khanal, and B. K. Kapoor, A cross-sectional study of lung functions in traffic police personnel at work in Kathmandu Valley, Nepal, Annals of Clinical Chemistry and Laboratory Medicine 1 (2015) 42.

[9] A. Gurung, and M. L. Bell, The state of scientific evidence on air pollution and human health in Nepal Environmental Research (2013) 124, 54.

[10] N. S. Thomaidis, E. B. Bakeas, and P. A. Siskos, Characterization of lead, cadmium, arsenic and nickel in $\operatorname{PM}(2.5)$ particles in the Athens atmosphere, Greece, Chemosphere 52 (2003) 959.

[11] M. Lippmann, K. Ito, J.-S. Hwang, P. Maciejczyk, and L.-C. Chen, Cardiovascular effects of nickel in ambient air, Environmental Health Perspectives 114 (2006) 1662.

[12] M. Franklin, P. Koutrakis, and J. Schwartz, Epidemiology (Cambridge, Mass.) 19 (2008) 680.

[13] A. S. Stender, K. Marchuk, C. Liu, S. Sander, M. W. Meyer, E. A. Smith, B. Neupane, G. Wang, J. Li, J.-X. Cheng, B. Huang, N. Fang, Single cell optical imaging and spectroscopy, Chemical Reviews 113 (2013) 2469.

[14] S. W. Hell, Far-Field Optical Nanoscopy, Science 316 (2006) 1153.

[15] B. Neupane, F. Chen, W. Sun, D. T. Chiu, G. Wang, Tuning donut profile for spatial resolution in stimulated emission depletion microscopy, Review of Scientific Instruments 84 (2013) 043701. 